\title{
Polymeric Pseudo-Liquid Membranes from Poly(2-ethylhexyl methacrylate)
}

\author{
By Daisuke NAITO, ${ }^{1}$ Masakazu YoshIKAWA, ${ }^{1, *}$ Shuichi MAEDA, ${ }^{2}$ and Hiroshi OKUSHITA ${ }^{2}$
}

Novel liquid membranes, which are named polymeric pseudo-liquid membranes, were constructed, using poly(2-ethylhexyl methacrylate), which showed rubbery state under operation conditions, as a membrane matrix. Dibenzo-18-crown-6 (DB18C6) was adopted as a model transporter and membrane transport performance through those polymeric pseudo-liquid membranes was investigated, adopting $\mathrm{KCl}$ as a model substrate. Poly(2-ethylhexyl methacrylate), P2EHMA, gave selfstanding liquid membranes under the experimental conditions, of which operation temperature was above its glass transition temperature. The polymeric pseudo-liquid membranes showed transport ability of $\mathrm{KCl}$. The flux value was linearly increased with the increase in DB18C6 content in the membrane and the membrane transport ability was greatly dependent on not only the molecular weight of membrane matrix, P2EHMA, but also the operation temperature. The present paper suggested that polymeric pseudo-liquid membranes are applicable to membrane separation as one of liquid membrane transport systems. KEY WORDS: Crown Ether / Liquid Membrane / Poly(2-ethylhecyl methacrylate) / Polymeric Pseudo-Liquid Membrane / Rubbery

Polymers / Transport /

Separation of a targeted substrate from a mixture containing compounds with similar molecular dimensions and showing similar chemical and/or physical properties is a difficult task in chemical industry. Such a targeted substrate, in general, has been separated by chromatography, especially liquid chromatography, which is usually operated as a batch process. Applying membrane separation technology to this field, the targeted molecule can be continuously separated from a mixture. In this case, membranes applied to separation should have molecular recognition sites or molecular recognition materials, which render them capable of separating substrates having similar molecular dimensions and properties. There are two ways to give membranes ability to separate quite similar substrates; one is a liquid membrane with a transporter for a target molecule, the other a fixed carrier membrane with a molecular recognition site or a molecular recognition material, which is covalently attached to the membrane material. Construction of liquid membrane is easier than that of a latter one, while there has been a drawback leading to the instability of liquid membranes. Generally liquid membrane has drawback in long-term stability, which is attributed to partial dissolution of the solvents, leaching of the carriers, and that of carriersubstrate complex. ${ }^{1-6}$ It is an important and interesting subject to develop stable and defect-free liquid membranes so that neither membrane solvent nor transporter may be lost to the aqueous phases. To this end, there have been reported various types of durable liquid membranes, such as 1) polymer liquid crystal composite membranes, ${ }^{7,8}$ 2) polymer inclusion membranes, ${ }^{9-12} 3$ ) organogel membranes, ${ }^{13,14}$ 4) supported polymeric liquid membranes, ${ }^{15-18}$ 5) stabilization of top layer of supported liquid membranes by interfacial polymerization ${ }^{19-21}$

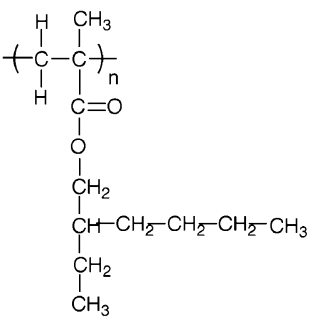

P2EHMA

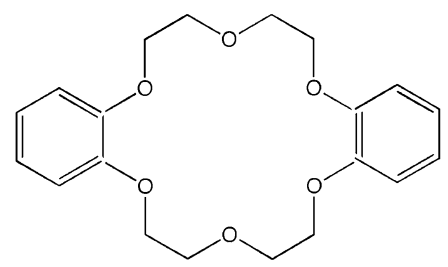

DB18C6
Figure 1. Chemical structures of P2EHMA and DB18C6.

or plasma polymerization, ${ }^{22}$ and 6) polymeric pseudo-liquid membranes. ${ }^{23,24}$ In the case that a candidate material with rubbery state under the operation condition gives durable selfstanding membranes, such a rubbery material could be applicable to the membrane matrix of polymeric pseudo-liquid membrane. In the present paper, poly(2-ethylhexyl methacrylate) with glass transition temperature of around $-10^{\circ} \mathrm{C}$ was adopted as a candidate membrane matrix for a novel polymeric pseudo-liquid membrane. The membrane performance of the polymeric pseudo-liquid membrane from poly(2-ethylhexyl methacrylate) was studied adopting dibenzo-18-crown-6 as a model transporter (Figure 1).

\section{EXPERIMENTAL}

\section{Materials}

2-Ethylhexyl methacrylate (2EHMA), ${ }^{25}$ 2,2'-azobis(2-methylpropionitrile) $(\mathrm{AIBN})^{26}$ and toluene ${ }^{27}$ were purified by

\footnotetext{
${ }^{1}$ Department of Biomolecular Engineering, Kyoto Institute of Technology, Matsugasaki, Kyoto 606-8585, Japan

${ }^{2}$ Polyamide Group, Organic Specialty Materials Research Laboratory, Corporate Research and Development, Ube Industries, Ltd., 1978-96, Kogushi, Ube 755-8633, Japan

*To whom correspondence should be addressed (Tel: +81-75-724-7816, Fax: +81-75-724-7800, E-mail: masahiro@kit.ac.jp).
} 
Table I. Conditions and results for the syntheses of P2EHMA

\begin{tabular}{|c|c|c|c|c|c|c|c|c|c|}
\hline & \multicolumn{2}{|c|}{ 2EHMA } & \multicolumn{2}{|c|}{ AIBN } & \multirow{2}{*}{$\begin{array}{c}\text { Toluene } \\
\mathrm{cm}^{3}\end{array}$} & \multicolumn{2}{|c|}{ P2EHMA } & \multirow{2}{*}{$10^{-3} M_{\mathrm{n}}$} & \multirow{2}{*}{$M_{\mathrm{w}} / M_{\mathrm{n}}^{\mathrm{b}}$} \\
\hline & $\mathrm{g}$ & $\mathrm{mol}$ & g & $\mathrm{mol}$ & & $\mathrm{g}$ & $\%$ & & \\
\hline P2EHMA-500 & 10.007 & $5.046 \times 10^{-2}$ & 4.412 & $2.522 \times 10^{-2}$ & 50.0 & 6.089 & 60.8 & 2.5 & 1.7 \\
\hline P2EHMA-005 & 8.001 & $4.032 \times 10^{-2}$ & 0.033 & $2.017 \times 10^{-4}$ & 40.0 & 7.411 & 92.6 & 120.0 & 5.7 \\
\hline
\end{tabular}

a Polymerization temp., $45^{\circ} \mathrm{C}$; polymerization time, $120 \mathrm{~h}$. ${ }^{\mathrm{b}}$ Determined by GPC.

conventional methods. Dibenzo-18-crown-6 (DB18C6), ethanol, hexane, chloroform and $\mathrm{KCl}$ were obtained from commercial sources and used as received. Tetrahydrofuran (THF) of HPLC grade was purchased and used without further purification. Water purified with an ultrapure water system (Simpli Lab, Millipore S. A., Molsheim, France) was used.

\section{Preparation of Poly(2-ethylhexyl methacrylate), P2EHMA}

The solution polymerizations of 2EHMA were carried out in glass ampoules at $45^{\circ} \mathrm{C}$ for $120 \mathrm{~h}$. The ampoules containing the prescribed amounts of 2EHMA and AIBN were degassed three times by the usual freeze-thaw cycles under high vacuum and then sealed. The reaction mixture was poured into ethanol/ hexane $(=2 / 1$; vol./vol. ratio), which was kept around $-50{ }^{\circ} \mathrm{C}$, and filtered. The resulting precipitate was collected. The polymers thus obtained were dried in vacuo.

\section{Characterization of P2EHMA}

${ }^{1} \mathrm{H}$ NMR spectra were recorded on a BRUKER AVANCE 500 FT NMR with tetramethylsilane (TMS) as an internal standard. Gel permeation chromatography (GPC) analysis was performed on a Shodex GPC SYSTEM-21, equipped with TSK-GEL G3000HXL and G5000HXL (Tosoh co.). Polystyrene standards were used for calibration and THF as eluent at a flow rate of $1.0 \mathrm{~cm}^{3} \mathrm{~min}^{-1}$. Differential scanning calorimetry (DSC) measurements were performed with Shimadzu DSC-60. The heating rate was fixed to be $20^{\circ} \mathrm{C} \mathrm{min}^{-1}$ and the sample was purged with nitrogen at a flow rate of $50 \mathrm{~cm}^{3} \mathrm{~min}^{-1}$. Measurements of dynamic viscoelastic properties and stress relaxation were carried out with a rotational rheometer, ARES (TA Instruments, Inc.) equipped with $25 \mathrm{~mm}$-diameter-parallel plates. The temperature for measurement ranged from 40 to $140^{\circ} \mathrm{C}$ and the angular frequency from $10^{-2}$ to $10^{1} \mathrm{rad} \mathrm{s}^{-1}$. The frequency dependence curves of storage modulus $G^{\prime}$ and loss modulus $G^{\prime \prime}$ of each sample at various temperatures can be superposed into master curves by shifting the curves along the frequency axis by a shift factor $\mathrm{a}_{\mathrm{T}}$. The temperature dependence of $\mathrm{a}_{\mathrm{T}}$ for two samples can be represented by the WLF type equations as follows: ${ }^{28}$

\section{P2EHMA-005:}

$$
\log \mathrm{a}_{\mathrm{T}}=-18.2\left(T-T_{\mathrm{r}}\right) /\left(209+T-T_{\mathrm{r}}\right), T_{\mathrm{r}}=80^{\circ} \mathrm{C}
$$

P2EHMA-500:

$$
\log \mathrm{a}_{\mathrm{T}}=-9.62\left(T-T_{\mathrm{r}}\right) /\left(183+T-T_{\mathrm{r}}\right), T_{\mathrm{r}}=80^{\circ} \mathrm{C}
$$

\section{Preparation of Polymeric Pseudo-Liquid Membranes}

Control membranes were prepared as follows: $700.0 \mathrm{mg}$ of P2EHMA was dissolved in $3.50 \mathrm{~cm}^{3}$ of $\mathrm{CHCl}_{3}$; the polymer solution thus prepared was poured into a TeflonPFA $75 \mathrm{~mm}$ diameter laboratory dish, and the solvent was allowed to evaporate at $25^{\circ} \mathrm{C}$ for $5 \mathrm{~h}$. The obtained membrane was dried at $50{ }^{\circ} \mathrm{C}$ for an additional $24 \mathrm{~h}$.

Polymeric pseudo-liquid membranes were prepared as follows; $700.0 \mathrm{mg}$ of P2EHMA and the prescribed amount of DB18C6, of which amount was $17.5 \mathrm{mg}, 35.0 \mathrm{mg}$, or $70.0 \mathrm{mg}$, were dissolved in $3.50 \mathrm{~cm}^{3}$ of $\mathrm{CHCl}_{3}$. Polymeric pseudo-liquid membranes were constructed from the polymer solution thus prepared as described above.

The thickness of the membrane was around $130 \mu \mathrm{m}$.

\section{Transport Experiment}

Transport of $\mathrm{KCl}$ through membrane was studied by the apparatus described in the previous paper. ${ }^{24}$ The membrane was sandwiched between two filter papers and they were secured tightly with Parafilm between two chambers of a permeation cell. In the present study, the membrane area was $3.0 \mathrm{~cm}^{2}$. The volume of each chamber was $40.0 \mathrm{~cm}^{3}$. $1.0 \times 10^{-4} \mathrm{~mol} \mathrm{~cm}^{-3}$ of aqueous $\mathrm{KCl}$ solution was placed in the left-hand side chamber (L-side) and deionized water in the right-hand side chamber (R-side). Experiments were carried out at $25^{\circ} \mathrm{C}, 32^{\circ} \mathrm{C}$ and $40^{\circ} \mathrm{C}$, respectively. Aqueous solutions in both chambers were stirred by magnetic stirrers. Concentration of $\mathrm{KCl}$ in the permeate side (R-side) was determined by conductometric analysis.

\section{RESULTS AND DISCUSSION}

Preparation of Poly(2-ethylhexyl methacrylate), P2EHMA

Results of polymerization are summarized in Table I. 2EHMA was polymerized at the mole ratios of radical initiator AIBN to 2EHMA of around 0.50 and 0.0050 , respectively. The former P2EHMA was named P2EHMA-500 and the latter P2EHMA-005, respectively. From the radical polymerization conditions, it was expected that the molecular weight of the former was lower than the latter. To confirm this, GPC analyses of two types of P2EHMA's were carried out. The molecular weight (number average molecular weight) increased from $2.5 \times 10^{3}$ to $1.2 \times 10^{5}$ with the decrease in the mole ratio of AIBN to 2EHMA from 0.50 to 0.0050 . Following the ratio of kinetic chain length calculated by adopting the concentration ratio of the radical initiator AIBN, ${ }^{29}$ the molecular weight of the latter would be ten times larger than the former. However, it was determined to be around 50 from GPC data.

Figure 2 shows DSC thermographs of those two types of P2EHMA's. The values of glass transition temperatures $\left(T_{\mathrm{g}}\right)$ for those polymers were determined to be $-14.3^{\circ} \mathrm{C}$ for 


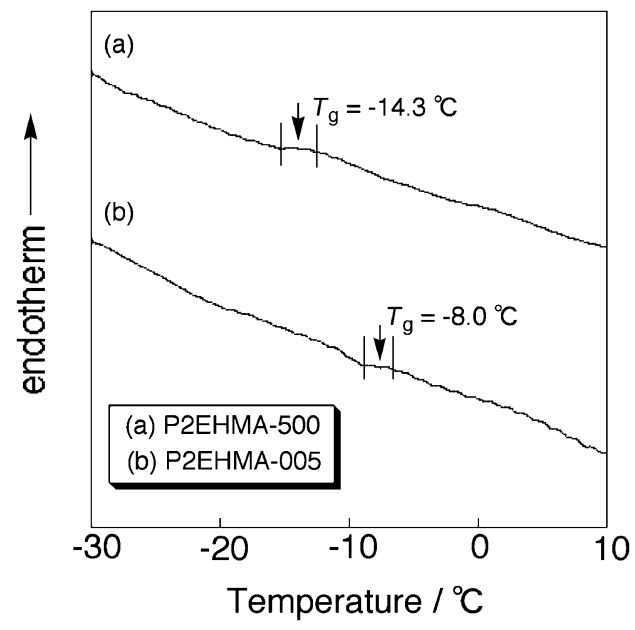

Figure 2. DSC thermogrphs of P2EHMA.

P2EHMA-500 and $-8.0^{\circ} \mathrm{C}$ for P2EHMA-005, respectively. The results that $T_{\mathrm{g}}$ for P2EHMA-500 was lower than that for P2EHMA-005 are due to the fact that the molecular weight of the former was around one fiftieth lower than the latter. From DSC results, it was confirmed that those two types of P2EHMA's prepared in the present study showed rubbery state at the operation temperatures of membrane transport experiments in the present study.

The maximum relaxation times of P2EHMA-005 and P2EHMA-500 evaluated from stress relaxation curves are $1.9 \mathrm{~s}\left(\right.$ at $140{ }^{\circ} \mathrm{C}$ ) and $6.5 \mathrm{~s}\left(\right.$ at $80^{\circ} \mathrm{C}$ ), respectively. Using the eq 1 and 2, the maximum relaxation times of P2EHMA-005 and P2EHMA-500 at $40^{\circ} \mathrm{C}$ are $4.5 \times 10^{8} \mathrm{~s}$ and $3.2 \times 10^{3} \mathrm{~s}$, respectively.

From those results described above, a liquid membrane from P2EHMA-500 was expected to transport $\mathrm{KCl}$ faster than that from P2EHMA-005. Since the diffusion coefficients of both transporter and transporter-substrate complex can be thought to be inversely proportional to the viscosity of medium, which is semi-empirical relation and is based on the Stokes-Einstein equation. ${ }^{30}$ This will be confirmed in the next section.

\section{Transport of $\mathrm{KCl}$ though the Membranes}

Membrane matrix forming ability of P2EHMA was investigated by adopting dibenzo-18-crown-6 (DB18C6) as a model transporter and $\mathrm{KCl}$ was adopted as a targeted substrate. Figure 3 shows time-transport curves of $\mathrm{KCl}$ through two types of polymeric pseudo-liquid membrane, consisting of P2EHMA-500 or P2EHMA-005. Those transport experiments were carried out at the constant temperature of $40^{\circ} \mathrm{C}$. The straight line for each transport experiment in Figure 3 showed a transport curve of $\mathrm{KCl}$, which was regarded as steady state for each experiment. As can be seen, $\mathrm{KCl}$ was slightly transported through both control membranes. Transport rate of $\mathrm{KCl}$ through membrane was increased with the increase in the amount of transporter in the membrane. Transport rate of $\mathrm{KCl}$ through P2EHMA-500 membrane seemed to be higher than that through P2EHMA-005 membrane. This might greatly
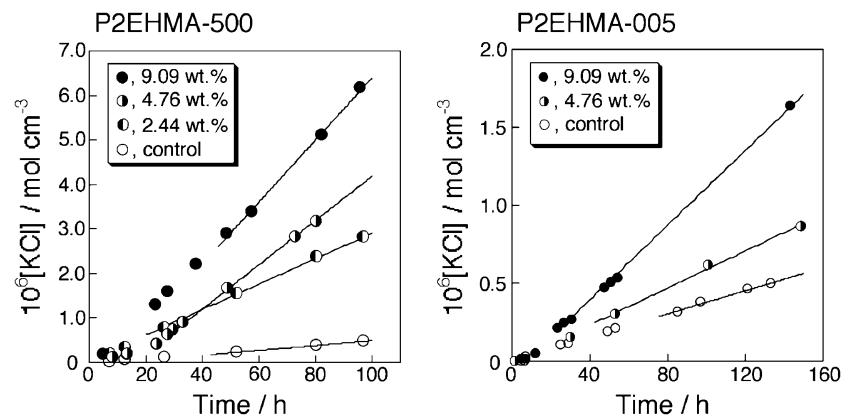

Figure 3. Time-transport curves of $\mathrm{KCl}$ through $\mathrm{P} 2 \mathrm{EHMA}$ liquid membranes. (Operation temp., $40^{\circ} \mathrm{C}(313 \mathrm{~K})$.)

$10^{3}[\mathrm{DB} 18 \mathrm{C} 6] / \mathrm{mol} \mathrm{cm}^{-3}$

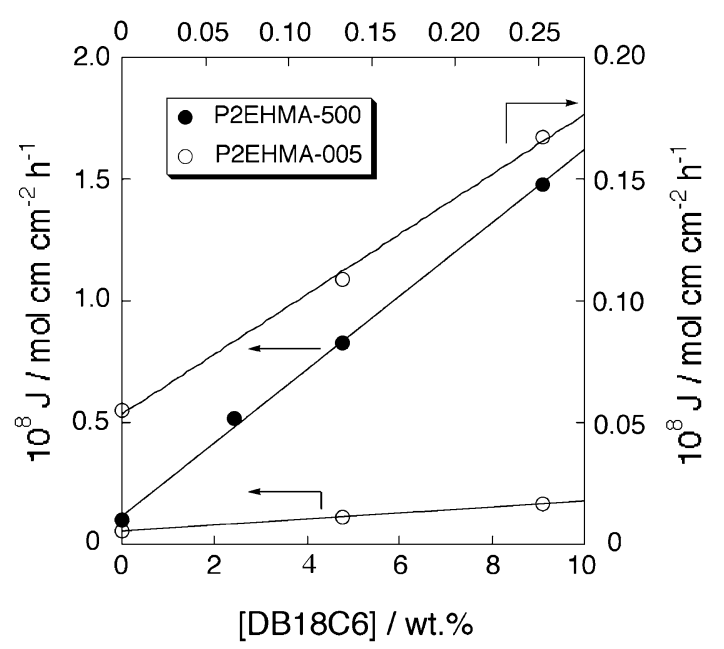

Figure 4. Relationship between $\mathrm{KCl}$ flux and DB18C6 concentration through P2EHMA liquid membranes.

attribute to the mobility of polymer chains, which was mainly governed by the difference in molecular weight. Figure 4 shows relationship between $\mathrm{KCl}$ flux through membrane and transporter concentration for two types of polymeric pseudoliquid membrane. In the figure, the concentration of transporter DB18C6 was calculated, assuming the density of P2EHMA to be $1.0 .^{31}$ As shown in Figure 3, both control membranes slightly transported $\mathrm{KCl}$. $\mathrm{KCl}$ flux values for both membranes increased linearly with the increase in DB18C6 concentration. The dependence of $\mathrm{KCl}$ flux on transporter concentration can be represented by eq (3). ${ }^{32,33}$

$$
J_{\mathrm{C}}=\frac{D_{\mathrm{CA}} k}{\delta} C_{\mathrm{CS}}^{2}+\frac{D_{\mathrm{CLA}} k K C_{\mathrm{L}}}{\delta} \frac{C_{\mathrm{CS}}^{2}}{1+k K C_{\mathrm{CS}}^{2}}
$$

From Figure 4, DB18C6 worked as a transporter in P2EHMA. In other words, P2EHMA played an important role as a liquid membrane matrix to isolate two aqueous phases, to dissolve transporter DB18C6 in it and to support DB18C6 to facilitate $\mathrm{KCl}$ transport through the membrane. In the present study, the transport rate of $\mathrm{KCl}$ through P2EHMA-500 liquid membrane was 12 times higher than that through P2EHMA-005 one. As 


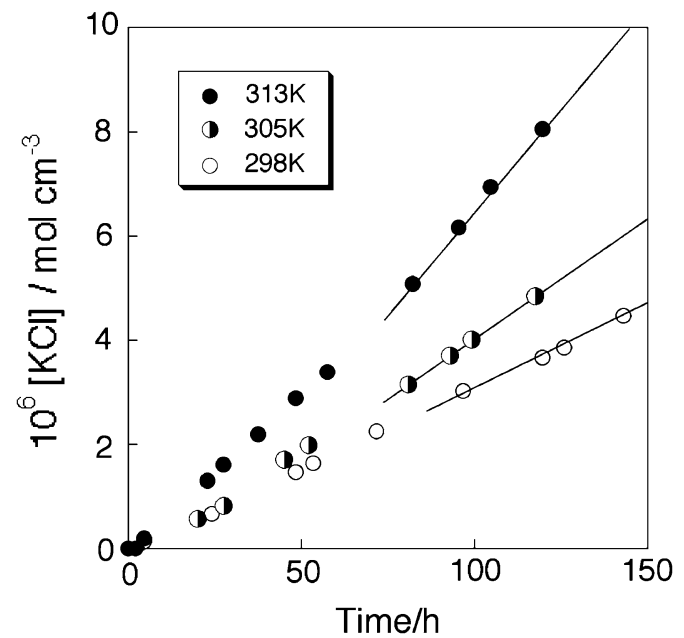

Figure 5. Dependence of $\mathrm{KCl}$ transport through P2EHMA-500 liquid membrane on operation temperature. (DB18C6 content in the membrane, 9.09 wt. \%.)

expected in the previous section, P2EHMA-500 liquid membrane, of which molecular weight was lower than P2EHMA005, gave higher flux than P2EHMA-005 membrane. As is well known, flux values are governed by two factors such as solubility and diffusivity following solution-diffusion theory. ${ }^{34}$ In the present study, solubilities of $\mathrm{KCl}$ into two types of membranes were assumed to be same even though those two membranes had different molecular weights. Diffusivities of both the free solute $(\mathrm{KCl})$ and the solute $(\mathrm{KCl})$ complexed with transporter, which were greatly dependent on viscosity of medium, in P2EHMA-500 liquid membrane should be higher than those in P2EHMA-005 membrane. The difference in diffusivity of substrate $\mathrm{KCl}$ in the membrane was thought to be the dominant factor to determine transport flux of $\mathrm{KCl}$. As a result, $\mathrm{KCl}$ was transported through $\mathrm{P} 2 \mathrm{EHMA}-500$ membrane faster than through P2EHMA-005 one.

If the membrane matrix showed glassy state under experimental conditions, $\mathrm{KCl}$ transport could be hardly observed. In addition, decrease in mobility of P2EHMA was expected to lead to decline of flux values of $\mathrm{KCl}$ transport. To this end, $\mathrm{KCl}$ transport through P2EHMA-500 with DB18C6 membrane was investigated at the operation temperature of $25^{\circ} \mathrm{C}(298 \mathrm{~K})$ and $32{ }^{\circ} \mathrm{C}(305 \mathrm{~K})$ in addition to that of $40^{\circ} \mathrm{C}(313 \mathrm{~K})$. Timetransport curves at various operation temperatures are shown in Figure 5. As can be seen, the slopes of time-transport curves at a steady state decreased with the drop in the experimental temperature. As shown in Figure 6, Arrhenius plot of $\mathrm{KCl}$ flux versus reciprocal of absolute temperature yield apparent energies of activation of the membrane transport. The activation energy of $\mathrm{KCl}$ transport through P2EHMA-500 with DB18C6 membrane was determined to be $49.1 \mathrm{~kJ} \mathrm{~mol}^{-1}$. At the moment, there have been few data of activation energy of $\mathrm{KCl}$ transport with polymeric pseudo-liquid membrane. In future, those values for various types of polymeric pseudo-liquid membranes will be considered in connection with $T_{\mathrm{g}}$ values of membrane matrices.

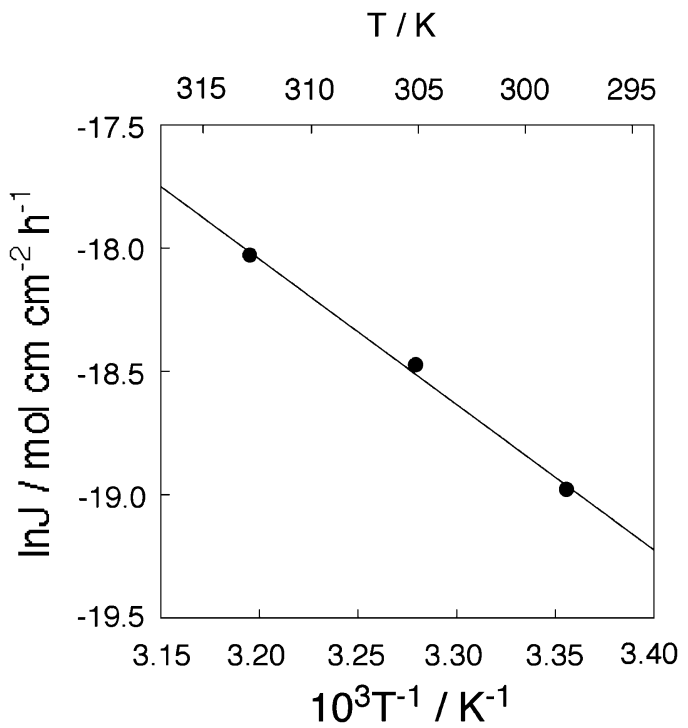

Figure 6. Temperature dependence of $\mathrm{KCl}$ transport through P2EHMA-500 liquid membrane. (DB18C6 content in the membrane, $9.09 \mathrm{wt} \%$.)

The transport result obtained in the present study was compared with those for other polymeric pseudo-liquid membranes previously studied in our laboratory, even though each operation temperature was different. The flux values at the transporter concentration of around $6.8 \times 10^{-5} \mathrm{~mol} \mathrm{~cm}^{-3}$ for three types of membranes are summarized in Table II. In those studies, DB18C6 was adopted as a model transporter. As can be seen, the present membrane from P2EHMA gave relatively higher flux value. As for the future study, it can be expected that polymethacrylate or polyacrylate esters showing lower $T_{\mathrm{g}}$ values than that of P2EHMA have potentials to give liquid membranes showing higher transport ability.

\section{CONCLUSIONS}

Novel liquid membrane systems were constructed, using poly(2-ethylhexyl methacrylate) (P2EHMA), which showed rubbery state under operation conditions, as a membrane matrix and dibenzo-18-crown-6 (DB18C6) as a model transporter. Those liquid membranes with rubbery polymers as membrane matrices were named polymeric pseudo-liquid membranes. The membrane performance was investigated, adopting $\mathrm{KCl}$ as a model substrate. P2EHMA gave selfstanding liquid membranes under the experimental conditions, of which operation temperature was above its glass transition temperature. The present polymeric pseudo-liquid membranes transported $\mathrm{KCl}$. The flux value was proportional to the DB18C6 concentration, implying that DB18C6 played as an important role of transporter in the membrane matrix of P2EHMA. The membrane transport ability was greatly governed by not only the molecular weight of membrane matrix, P2EHMA, but also the operation temperature. The present paper suggested that polymeric pseudo-liquid membranes are applicable to membrane separation as one of liquid membrane transport systems. 
Table II. Summary of transport through the polymeric pseudo-liquid membranes

\begin{tabular}{|c|c|c|c|c|}
\hline \multirow{2}{*}{ Polymer } & [DB18C6] & Thickness & Area & $\mathrm{J}$ (ions) \\
\hline & $\mathrm{mol} \mathrm{cm}^{-3}$ & $\mathrm{~cm}$ & $\mathrm{~cm}^{2}$ & $\mathrm{~mol} \mathrm{~cm} \mathrm{~cm}^{-2} \mathrm{~h}^{-1}$ \\
\hline P2EHMA-500 & $6.77 \times 10^{-5}$ & $1.33 \times 10^{-2}$ & 3.0 & $5.2 \times 10^{-9}(\mathrm{KCl})$ \\
\hline \multirow[t]{2}{*}{ Comb copolymer ${ }^{b}$} & $6.80 \times 10^{-5}$ & $3.3 \times 10^{-3}$ & 3.0 & $4.9 \times 10^{-11}(\mathrm{KCl})$ \\
\hline & $6.80 \times 10^{-5}$ & $2.6 \times 10^{-3}$ & 3.0 & $1.6 \times 10^{-11}(\mathrm{NaCl})$ \\
\hline ABA block copolymer ${ }^{\mathrm{C}}$ & $6.80 \times 10^{-5}$ & $5.0 \times 10^{-3}$ & $4.5 \times 10^{-5}$ & $3.1 \times 10^{-10}(\mathrm{NaCl})$ \\
\hline
\end{tabular}

a at $25^{\circ} \mathrm{C}$; present work. bat $30^{\circ} \mathrm{C}$; cited from ref $35 .{ }^{\mathrm{c}}$ at $60^{\circ} \mathrm{C}$; cited from ref 24 .

Comb copolymer

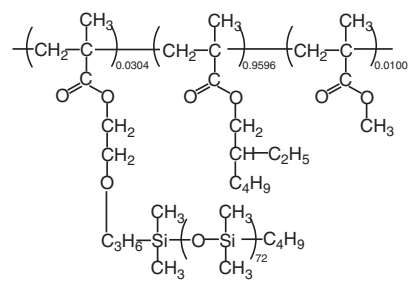

ABA block copolymer

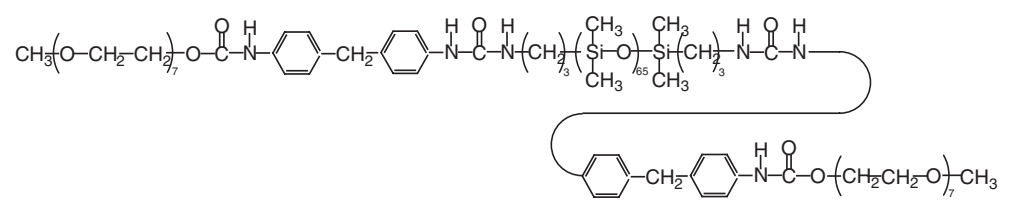

$C_{\mathrm{CS}}=$ concentration of the diffusing solutes in the source phase

$C_{\mathrm{L}}=$ total concentration of complexed and uncomplexed transporter in the membrane

$D_{\mathrm{CA}}=$ diffusion coefficient of the free solute

$D_{\mathrm{CLA}}=$ diffusion coefficient of the complexed solute

$J_{\mathrm{C}}=$ total flux of the diffusing solute across the membrane

$k=$ partition coefficient of the solute between water and the organic membrane

$K=$ equilibrium constant for the association

$\delta=$ membrane thickness

Received: May 8, 2009

Accepted: July 30, 2009

Published: September 16, 2009

\section{REFERENCES}

1. R. Danesi, L. Reichley-Yinger, and P. G. Rickert, J. Membr. Sci., 31, 117 (1987)

2. H. Takeuchi, K. Takahashi, and W. Goto, J. Membr. Sci., 34, 19 (1987).

3. F. F. Zha, A. G. Fane, C. J. D. Fell, and R. W. Schofield, J. Membr. Sci., 75, 69 (1992).

4. F. F. Zha, A. G. Fane, and C. J. D. Fell, J. Membr. Sci., 107, 59 (1995).

5. F. F. Zha, A. G. Fane, and C. J. D. Fell, J. Membr. Sci., 107, 75 (1995).

6. X. J. Yang and A. G. Fane, J. Membr. Sci., 156, 251 (1999).

7. S. Shinkai, S. Nakamura, S. Tachiki, O. Manabe, and T. Kajiyama, J. Am. Chem. Soc., 107, 3363 (1985).
8. S. Shinkai, K. Torigoe, O. Manabe, and T. Kajiyama, J. Chem. Soc., Chem. Commun., 933 (1986).

9. M. Sugiura, M. Kikkawa, and S. Urita, Sep. Sci. Technol., 22, 2263 (1987).

10. A. J. Schow, R. T. Peterson, and J. D. Lamb, J. Membr. Sci., 111, 291 (1996).

11. J. A. Riggs and B. D. Smith, J. Am. Chem. Soc., 119, 2765 (1997).

12. S. P. Kusumocahyo, T. Kanamori, K. Sumaru, S. Aomatsu, H. Matsuyama, M. Teramoto, and T. Shinbo, J. Membr. Sci., 244, 251 (2004).

13. A. M. Neplenbroek, D. Bargeman, and C. A. Smolders, J. Membr. Sci., 67, 149 (1992).

14. E. Miyako, T. Maruyama, N. Kamiya, and M. Goto, Membrane, 29, 236 (2004)

15. S. V. Ho, O. W. Sheridan, and E. Krupetsky, J. Membr. Sci., 112, 13 (1996).

16. P. Harriott and S. V. Ho, J. Membr. Sci., 135, 55 (1997).

17. S. V. Ho, Environ. Prog., 18, 273 (1999).

18. M. G. Dastgir, L. G. Peeva, G. Peeva, and A. G. Livingston, Chem. Eng. Sci., 60, 7034 (2005).

19. A. J. B. Kemperman, H. H. M. Rolevink, D. Bargeman, Th. van den Boomgaard, and H. Strathmann, J. Membr. Sci., 138, 43 (1998).

20. Y. Wang, Y. S. Thio, and F. M. Doyle, J. Membr. Sci., 147, 109 (1998).

21. M. C. Wijers, M. Jin, M. Wessling, and H. Strathmann, J. Membr. Sci., 147, 117 (1998).

22. X. J. Yang, A. G. Fane, J. Bi, and H. J. Griesser, J. Membr. Sci., 168, 29 (2000)

23. W. Meier, C. Nardin, and M. Winterhalter, Angew. Chem., Int. Ed., 39, 4599 (2000).

24. T. Sakiyama, T. Aoki, and M. Yoshikawa, Membrane, 29, 377 (2004).

25. D. P. Perrin and W. L. F. Armarego, "Purification of Laboratory Chemicals," 3rd ed., Pergamon Press, Oxford, 1988.

26. J. L. Kice, J. Am. Chem. Soc., 76, 6274 (1954).

27. J. A. Riddick, W. B. Bunger, and T. K. Sakano, "Organic Solvents," 
4th ed., Wiley, New York, 1986.

28. J. D. Ferry, "Viscoelastic Properties of Polymers," 3rd ed., Wiley, New York, 1980.

29. G. Odian, "Principles of Polymerization," 4th ed., John Wiley \& Sons, Hoboken, 2004.

30. J. G. A. Bitter, "Transport Mechanisms in Membrane Separation Processes," Plenum Press, New York, 1991.

31. B. Kine and R. W. Novak, in "Encyclopedia of Polymer Science and Engineering” 2nd ed., H. F. Mark, N. M. Bikales, C. G. Overberger, and G. Menges, Ed., John Wiley \& Sons, New York, 1985, Vol. 1, pp. 258.

32. C. F. Reusch and E. L. Cussler, AIChE J., 19, 736 (1973).

33. J. D. Lamb, J. J. Christensen, S. R. Izatt, K. Bedke, M. S. Astin, and R. M. Izatt, J. Am. Chem. Soc., 102, 3399 (1980).

34. M. Mulder, "Basic Principles of Membrane Technology," 2nd ed., Kluwer Academic Publishers, Dordrecht, 1996.

35. Unpublished data; part of results has been presented at ICOM2005 (Tu04E-1) and the Membrane Symposium 2004 (201) of the Membrane Society of Japan. 